\title{
As subordinações das causas em Aristóteles
}

\section{The subordination of causes in Aristotle}

\author{
Thayrine Vilas Boas \\ Graduação em andamento em Filosofia (2013). Universidade Federal de Lavras - UFLA
}

\begin{abstract}
Resumo: Ao desenvolver sua teoria causal no livro II da Física, Aristóteles explica e exemplifica cada uma das causas separadamente, como se existissem por si só. Mas, ao se fazerem presentes nos entes, encontram-se ligadas uma às outras, expressando uma relação de subordinação entre si. Cada ente possui uma causa de um dos quatro tipos em sua formação, sendo uma causa material, uma formal, uma eficiente e uma final. Desse modo, meu objetivo é apresentar como as causas existem nos entes a partir de seus diferentes modos de subordinações, visando, principalmente, como cada uma se relaciona com causa final.
\end{abstract}

Palavras-chave: ente; causas; Aristóteles.

Abstract: In developing his causal theory in Book II of Physics, Aristotle explains and exemplifies each of the causes separately, as if they existed by themselves. But in making themselves present in the entities, they are linked one to the others, expressing a relation of subordination among themselves. Each entity has a cause of one of the four types in its formation, being a material, a formal, an efficient and an end cause. Thus, my goal is to present how the causes exist in entities from their different modes of subordination, aiming, mainly, as each relates to the final cause.

Keywords: entity; causes; Aristotle. 
Ao desenvolver sua teoria causal no livro II da Física, Aristóteles explica e exemplifica cada uma das causas separadamente, como se existissem por si só, as classificando em: a causa material como o princípio de que algo provém, aquilo que se encontra primeiro e em maior quantidade; a causa formal, "aquilo que o ser é" e seus gêneros; a causa eficiente ou princípio de movimento como "aquilo de onde provém"; e a causa final, "aquilo em vista de quê".

Contudo, ao se fazerem presentes nos entes, as causas se encontram ligadas umas às outras, com o acréscimo de uma relação de subordinação entre elas. Cada ente possui uma causa de cada um dos quatro tipos em sua formação, sendo uma causa material, uma formal, uma eficiente e uma final, ou seja, uma causa depende da outra para a formação das coisas na natureza. Assim como o filósofo diz:

“Há várias causas para uma mesma coisa, não por concomitância; por exemplo, tanto a arte de esculpir como o bronze são causas da estátua [...] - uma é como matéria, a outra é aquilo de onde provém o movimento" ${ }^{1}$ (195a 5-8).

Desse modo, como cada ente possui mais de uma causa, cada uma delas irá dizer sobre determinado princípio, o qual pode ser formal, material, eficiente ou final, que se apresenta primeiro e em maior quantidade na coisa, visto que um mesmo ente pode possuir mais de uma causa de cada tipo ${ }^{2}$. Assim como no exemplo citado, mostram-se dois tipos de causa da estátua, uma causa material e uma causa eficiente; contudo, ainda se pode acrescentar que a mesma estátua vem a ter uma causa formal, que é a forma em que ela obtém, e uma causa final, que é o motivo que levou o escultor a esculpir aquela estátua daquele modo e em tal material.

A partir de tal passagem torna-se possível notar que cada coisa possui um conjunto de causas para se constituir, que podem ser uma de cada tipo, mas dentre tais causas, podem-se destacar subordinações entre elas, o que acaba por manter um vínculo maior de determinada causa com outra em alguns momentos, como destacarei mais adiante.

Tais subordinações podem vir a ocorrer de diversos modos, envolvendo duas, três ou os quatro tipos de causas, dentre as quais algumas podem se destacar:

A primeira subordinação é entre a causa material e a causa formal, a qual diz respeito à matéria e à forma, que são os elementos básicos para a formação de algo no mundo e que permitem transformar em ato algo que só existia em potência. Assim como Enrico Berti diz em Estrutura e Significado da Metafísica de Aristóteles, (pág. 101): "a noção de matéria e forma, que são os componentes de todos os objetos físicos [...]. A matéria é aquilo do qual são feitos, e a forma é o modo no qual são organizados". A matéria e a forma são ainda os dois modos que tornam possível dizer a natureza, e sob esse aspecto Aristóteles diz:

“Denomina-se natureza a primeira matéria que subjaz a cada um dos que possuem em si mesmos princípio de movimento ou mudança; mas de outra maneira, denomina-se natureza a configuração e a forma segundo a definição"3 (1932 28-30).

Contudo, no âmbito daquilo que é conforme a natureza, a forma prevalecerá sob a matéria, sendo ela quem determina suas características, assim como Lucas Angioni em "As quatro causas na filosofia da natureza de Aristóteles" diz: "[...] a forma da estátua é que explica por que seu material deve ser de tal e tal qualidade: deve ser o material propício a comportar a figura com as propriedades relevantes".

\footnotetext{
${ }^{1}$ ARISTÓTELES. Física. Tradução e comentários do Lucas Angioni. Campinas, SP: Ed. da UNICAMP, 2009. 195a 5-8.

${ }^{2}$ Um exemplo de ente que possui mais de uma causa do mesmo tipo pode ser a cama, em que sua causa material é a madeira, mas também são os pregos que unem a madeira. No caso, pela madeira se encontrar primeiro e em maior quantidade, visto que ela constitui a maior parte da cama, ela será considerada a causa material principal.

${ }^{3}$ ARISTÓTELES. Física. Tradução e comentários do Lucas Angioni. Campinas, SP: Ed. da UNICAMP, 2009. 193a 28-30.
} 
Retomando a citação de Aristóteles, a partir dela torna-se possível falar, também, de outro tipo de subordinação, que é a relação da causa material com a causa eficiente, em que a matéria deve possuir princípio de movimento para que possa existir; tal princípio de movimento pode ser interno, quando diz respeito à natureza, ou pode ser externo, se diz respeito à técnica.

Quanto à relação da causa formal com o princípio de movimento/ causa eficiente, Aristóteles diz: "A natureza dos que possuem em si mesmos princípio de movimento é a configuração e a forma, que não é separável a não ser em definição"4 (193b 3-4). Ou seja, o princípio de movimento ligado à matéria possui sua natureza na forma, que orienta tal movimento a fim de se fazer chegar a forma necessária àquela matéria; em outras palavras, é o princípio de movimento que permite à matéria adquirir determinada forma.

O filósofo ainda diz em 199a 30-32, “Uma vez que a natureza édupla, uma como matéria, outra, como forma e, dado que esta última é acabamento e as demais coisas são em vista do

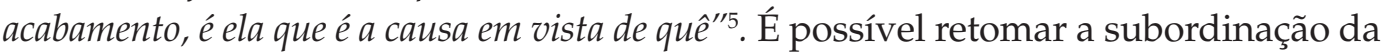
causa material com a formal, mas também, falar da subordinação entre a causa formal e a final, já que Aristóteles diz que a causa formal é a causa "em vista de quê", mas sendo o "em vista de quê" o fim que as coisas buscam alcançar.

Há a ligação da causa formal com a final, ao passo que o princípio de movimento permite à matéria adquirir determinada forma, mas tal forma diz respeito ao fim daquela coisa, sendo que é a causa final que determinará as características necessárias à forma para cumprir sua finalidade. Cito novamente Aristóteles, em 193b 16-17: "Mas o que é que nasce? Não aquilo a partir de quê, mas sim aquilo em direção a quê: portanto a forma é a natureza" ${ }^{6}$, onde se torna possível entender que a coisa não nasce de sua forma, mas sim daquilo a que ela está determinada. E como Angioni diz em seu artigo: "[...] o fator que explica por que a estátua tem a forma que lhe foi atribuída [...] é o propósito para o qual a estátua foi concebida". Entretanto, mesmo a causa formal sendo quem permite a realização da causa final, ela não é capaz de se realizar sem seu fim.

É possível dizer também que há subordinação da causa eficiente e da causa final, sendo que a matéria só adquire a forma pelo princípio de movimento, em que a forma já está associada à causa final. Aristóteles diz que "A natureza tomada como vir a ser é processo em direção à natureza"7 (193b12), ou seja, o princípio de movimento permite a coisa / o ente ir em direção ao seu fim, o qual está atrelado à causa formal, que possibilita a coisa adquirir as características necessárias para seu fim. Mas, em tal processo, o movimento exercido em direção ao fim o leva também em direção à natureza, sendo que tais movimentos só se tornam possíveis quando ocorrem nas coisas por natureza e nas conforme a natureza, as quais se dizem através da forma e da matéria.

Outra forma de subordinação é a causa formal e material com a causa eficiente e a final, sendo que a matéria e forma se fazem necessárias para a existência das coisas no mundo, mas elas não seriam possíveis sem o princípio de movimento e o fim, que proporcionam movimento a elas para se tornarem o que são. Desse modo a causa eficiente e a causa final.

\footnotetext{
${ }^{4}$ Idem. 193b 3-4.

${ }^{5}$ ARISTÓTELES. Física. Tradução e comentários do Lucas Angioni. Campinas, SP: Ed. da UNICAMP, 2009. p. 47.199a 30-32

${ }^{6}$ Idem. 193b 16-17.

${ }^{7}$ Idem. 193b 12.
} 
“São dois os princípios que movem naturalmente, dos quais um não é natural, pois não tem princípio de movimento em si mesmo. Algo é de tal tipo na medida em que move sem ser movido: isso é acabamento e o em vista de quê" 8 (198a 35 - 198b 3).

Sendo o princípio de movimento natural a causa eficiente, pois se encontra ligada diretamente à matéria, e a causa final é o movimento não natural, sendo que ela direciona a causa eficiente em direção ao fim, mas ele mesmo não possui capacidade de movimento; ou seja, a causa final será uma movimento que guiará a causa eficiente do ente a cumprir seu fim, mas tal movimento é feito sem que a causa final se mova, sendo um movimento não natural, que "move sem ser movido".

Outro modo de subordinação existente entre as causas aristotélicas é a da causa material, eficiente e final em relação à causa formal, como se formassem apenas duas causas, sendo que a matéria é quem possui princípio de movimento, e é tal princípio que direciona para a causa final, fazendo com que as três causas possam ser reunidas em uma única, enquanto que a causa formal é que proporciona a existência da coisa e irá atribuir os elementos necessários, permitindo dizer que "Em tudo aquilo e que há algum acabamento, é em vista dele que se faz aquilo que é anterior e o seguinte" (199a 8-9), ou seja, é a forma que irá determinar as demais causas.

Em contrapartida, a causa formal é fundamentada pela causa final, permitindo fazer uma última subordinação, que é a das causas material, formal e eficiente em relação à causa final, em que o filósofo diz que: "Estas três convergem para uma só coisa: o "o que é" e aquilo em vista de quê são uma só, e lhes é especificamente idêntico aquilo de que

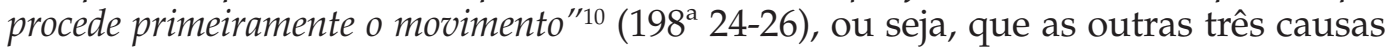
convergem para a causa final, visto que a finalidade da coisa deve se apresentar primeiro, determinando assim os elementos necessários para sua constituição; desse modo, tendo o fim já determinado, é possível saber qual matéria é necessária para a realização de tal fim, assim como qual será o movimento que levará a tal fim e a forma que a matéria deverá obter. Em outras palavras, é o fim que irá determinar todas as características necessárias, e, embora ele só se realize quando a coisa / o ente já estiver constituído, ele deve se apresentar antes disso ocorrer, para que haja a escolha das características que são por necessidade.

É possível justificar esta última subordinação quando Aristóteles diz em $198^{a}$ 10-14: "Por que a natureza se conta entre as causas que são em vista de algo [...]: 'visto que o quente é naturalmente de tal qualidade, tais e tais coisas são e vêm a ser por necessidade'"11.

Com isso, torna-se possível dizer que as causas se relacionam de diversos modos, mas tais modos acabam por se encontrar ligados um ao outro na medida em que cada subordinação acaba por estar ligada à outra, fazendo com que haja um entrelaçamento entre os quatro tipos de causas.

Concluo fazendo referência à conclusão que Lucas Angioni faz em seu artigo "As quatro causas na filosofia da natureza de Aristóteles", em que ele diz que: "[...] para o qual existam causas de cada um dos quatro tipo, as quatro causas se subordinam entre si de tal modo que uma delas fornece explicações mais completas, que envolvem e fundamentam as explicações subordinadas", e que "No modelo de subordinação causal que encontramos nos textos de Aristóteles, a causa final é a preponderante, que subordina as demais".

Em outras palavras, e tendo a concordar com as palavras de Angioni, a explicação de cada uma das causas busca fundamentar as outras, e a causa que é capaz de fundamentar todas é a causa final, a qual é preponderante por sustentar a causa formal, que fundamenta, por sua vez, a causa material, que possui em si a causa eficiente.

\footnotetext{
${ }^{8}$ ARISTÓTELES. Física. Tradução e comentários do Lucas Angioni. Campinas, SP: Ed. da UNICAMP, 2009. p. 47. 198a $35-198 b 3$

${ }^{9}$ Idem. 199a 8-9.

${ }^{10}$ Idem. 198a 24-26.

${ }^{11}$ ARISTÓTELES. Física. Tradução e comentários do Lucas Angioni. Campinas, SP: Ed. da UNICAMP, 2009. p. 47 . 198a 10-14.
} 
Correspondência: Thayrine Vilas Boas. Universidade Federal de Lavras - UFLA. Departamento de Ciências Humanas. Av. Doutor Sylvio Menicucci, 1001. Lavras - MG - Brasil. CEP: 37200-000. E-mail: tata.am17@ hotmail.com

Conflito de interesses: Nenhum

Todos os autores leram e aprovam a versão final submetida à revista Em curso. 


\section{Bibliografia}

ARISTÓTELES. Física. Tradução e comentários do Lucas Angioni. Campinas, SP: Ed. da UNICAMP, 2009.

. Metafísica. 3 vols. Introdução, tradução e comentários de Giovanni Reale. 2. Ed. São Paulo, SP: Edições Loyola, 2005.

. As Partes dos Animais -Livro I. Tradução e comentários do Lucas Angioni. Cadernos de História e Filosofia da Ciência. Série 3, v.9, n. especial, 1999.

ANGIONI, Lucas. As quatro causas na filosofia da natureza de Aristóteles. Anais de Filosofia Clássica, vol. $\mathrm{V} \mathrm{n}^{\circ} 10,2011$.

BERTI, Enrico. Estrutura e Significado da Metafísica de Aristóteles. Tradução de José Bortolini. São Paulo, SP: Editora Paulus, 2012.

Recebido em: 22/Mar/2017 - Aceito em: 06/Out/2017. 